\title{
Nurses' experiences of communicating respect to patients: Influences and challenges
}

\author{
Claudine Clucas , Hazel Chapman and Andrew Lovell \\ University of Chester, UK
}

\begin{abstract}
Background: Respectful care is central to ethical codes of practice and optimal patient care, but little is known about the influences on and challenges in communicating respect.

Research question: What are the intra- and inter-personal influences on nurses' communication of respect?

Research design and participants: Semi-structured interviews with 12 hospital-based UK registered nurses were analysed using interpretative phenomenological analysis to explore their experiences of communicating respect to patients and associated influences.

Ethical considerations: The study was approved by the Institutional ethics board and National Health Service Trust.

Findings: Three interconnected superordinate themes were identified: 'private self: personal attitudes', 'outward self: showing respect' and 'reputational self: being perceived as respectful'. Respectful communication involved a complex set of influences, including attitudes of respect towards patients, needs and goals, beliefs around the nature of respectful communication, skills and influencing sociocultural factors. A tension between the outward self as intended and perceived presented challenges for nurses' reputational self as respectful, with negative implications for patient care. Discussion: The study offers an in-depth understanding of intra- and inter-personal influences on communicating respect, and sheds light on challenges involved, helping provide practical insights to support respectful care.

Conclusion: Findings stress the need for improved conceptualisations of respect in healthcare settings to formally recognise the complex attitudinal and socially constructed nature of respect and for appropriate professional training to improve its communication.

Keywords
\end{abstract}

Attitudes, codes of ethics, communication, interpretative phenomenological analysis, nurse-patient relationship, respect

\section{Introduction}

Respectful care is central to ethical codes of practice in healthcare systems around the world 1,2 and needed for optimal patient care. Patient reports and complaints of being disrespected by healthcare professionals $3-5$ and disparities in experiences of respectful cares suggest this ethical imperative is not being fully achieved. Feeling respected means feeling worthy or valuable in interactions with others. 7 It is critical for patients' emotional well-being and good provider-patient relationships-11 and associated with adherence to advice, receipt of optimal preventive care and seeking necessary care.12,13 Good provider-patient relationships are necessary for patient-centred medical care, leading to high-quality care and positive patient outcomes.14,15 However, little attention has been paid to how respectful care can be achieved in practice. In particular, little is known about the influences on and challenges in communicating respect, a state of affairs that is complicated by a lack of a unified body of literature on respect. Respect is often operationalised as a set of behaviours that recognise a person's worth and value, such as ensuring patient privacy and treating patients as equals, 16 or in nursing and medical ethics, protecting the patient's autonomy.17 However, respect also involves judgements regarding the respect-worthiness of the object of respect and feelings relating to experiencing the person as valuable; it is an attitude.18-21 Two main bases for respect have been identified: humanity, which makes people inherently worthy (this form is referred to as unconditional or recognition respect) and character-related merits and achievements (conditional or appraisal respect).18,22 Respect differs from the attitude of liking, in that it is owed to a person who demonstrates attributes that command recognition and appreciation, regardless of personal affinities and needs.21 While unconditional respect features in the nursing literature, with the expectation that nurses value patients as persons, it is not always clearly distinguished from the Rogerian 23 concept of unconditional positive regard;1,17,24 it may only imply a basic level of respect for all people in view of their humanity, as opposed to full acceptance of the person, but research is needed on the topic. Moreover, conditional respect is largely overlooked. However, a small body of research has shown physicians to have less respect for certain types of patients, such as younger patients, patients not known as well by physicians and patients with higher body mass index, 17,25 suggesting healthcare providers may have difficulty in respecting all 
patients equally. However, it is uncertain if these findings apply to nurses as well; factors influencing nurses' evaluations of patients' worth and value - attitudes of respect, as opposed to liking - have not been investigated. There are stronger expectations that nurses should respect patients than like them, and it is possible to value a person you do not like.21

It is also uncertain if nurses' attitudes of respect towards patients influence their behaviours of respect. Only one study examined the relationship between healthcare professionals' attitudes and behaviours of respect. This quantitative observational study in the United States showed that physicians shared more information and showed more positive affect to patients whom they respected; 17 however, the direction of the findings was unclear with patients' behaviour possibly influencing the physicians' behaviour and attitudes, and the study did not measure physicians' attitudes towards patient-centred or respectful care, or personal communication goals, which could have confounded the findings.26 According to the theory of planned behaviour,27 strong role expectations and professional obligations relating to respectful care, 28 and beliefs in the importance of respect, are likely to motivate respectful behaviour regardless of potentially conflicting personal feelings or beliefs towards patients. This might be particularly so in nurses for whom being caring and respectful is a particularly defining aspect of their professional identity globally.29 It is unknown if attitudes of respect conflict with respectful communication intentions, or how nurses experience and negotiate these potential differences. An in-depth understanding of intra- and inter-personal influences on nurses' communication of respect, such as attitudes, needs, as well as beliefs is necessary.26,30 If nurses are unclear about what respect is and how it should be shown, this may lead to misunderstandings over ethical expectations in practice. Therefore, the present study aimed to explore registered nurses' experiences of communicating respect to patients in hospital-based nursing encounters and associated influences in order to clarify intra- and inter-personal influences on their communication of respect and inform future support for nurses to deliver respectful and ethical care for positive patient outcomes.

\section{Method}

Using Interpretative Phenomenological Analysis (IPA), an in-depth exploration and analysis of individual accounts was utilised to understand the complexity of nurses' lived experiences of communicating respect to patients and associated influences.31

\section{Participants and procedure}

A total of 12 registered nurses were recruited from a public hospital in England using purposive sampling. The inclusion criteria were (1) having nurse registration status and (2) currently working in a UK National Health Service (NHS) hospital. To facilitate recruitment, given the sensitive nature of the research, participants were recruited by practice education facilitators who provided study information and invited them to attend an individual meeting with the researcher to discuss the study further if interested in participating. A total of 12 participants met with the researcher (H.M.C.) of 20 nurses approached (60\% positive response rate) and were interviewed individually on-site in a private room. A sample size of 12 is considered large for IPA, given its idiographic nature, intensive in-depth analysis of each participant's account, and representation of differences and similarities in experiences between participants.31 Sample characteristics can be found in Table 1.

\section{Data collection}

Face-to-face semi-structured interviews took place in August 2014 and lasted about 29-96 (M 1/4 61) min. They were digitally audio-recorded and transcribed verbatim.

The interviewing researcher was a registered nurse and university nurse educator and was introduced as such to participants. None knew her beforehand. The interview schedule asked participants about the importance of respect in their nursing practice, what respect for patients meant to them, expectations and behaviours of respect in practice, factors influencing their respect for patients (including challenges and facilitating factors) and what they believed influenced patients' respect for them and was used flexibly to allow for exploration of responses and unanticipated themes. Several of the interview questions had previously been piloted in student nurses. 28

Table 1. Sample characteristics.

Characteristic Sample

Gender 11 females, 1 male

Age 30-59 (mean $1 / 4$ 46) years

Time practising as registered nurse: $4-34$ (mean $1 / 414.29$ ) years

Area of work 4 elderly people ward, 2 breast care unit, 2 intensive/critical care, 1 stroke unit, 1 planned surgery, 1 pre-assessment clinic and 1 medical ward.

\section{Ethical considerations}


Participants were told that the study was interested in their experiences of respect in order to support nurses in caring respectfully for patients and were reassured about data anonymisation and confidentiality and that their participation would not affect their employment. Participants provided written consent before being interviewed. Participants are referred to by non-gender-specific pseudonyms to protect anonymity. The study was approved by the University Health and Social Care Ethics Committee (approval iD: RESCO114-

473) and the NHS trust Research and Development committee.

\section{Analysis}

IPA is an idiographic method that seeks to make sense of participants who are themselves trying to make sense of their experiences.31 We followed the steps and guidelines by Smith et al.31 Each transcript was analysed in depth one at a time. First, we read the transcript several times, familiarising ourselves with the content. Second, line-by-line coding was applied focusing on the participants' experiential concerns and cares. Third, accounts were interrogated by searching for repetitions, contradictions and any imagery employed. Key issues or themes were then identified. Two of the authors (C.C. - a female psychologist and H.M.C. - a female nurse) each analysed six transcripts and met frequently to discuss their independent analysis of the transcripts, ensuring the themes were supported by the data, mindful of their influence in the data analysis process. A third author (A.L. a male sociologist) analysed three of the transcripts; additional themes identified were considered in relation to the other transcripts. This process ensured rigour and credibility of analysis.32 The themes were then clustered into superordinate themes and compared across cases. Participants were given the opportunity to comment on the analysis (referred to as 'member checking') 32 to provide an additional credibility check. Interviews were carried out when nurses were under negative public scrutiny, 33 which could have affected participants' accounts.

\section{Results}

Table 2 lists the three superordinate themes identified, along with their subthemes, concerning nurses' experiences of communicating respect to patients and associated intra- and inter-personal influences at the level of the private, outward and reputational self.

\section{Private self: personal attitudes towards patients}

All nurses strongly valued respectful care and described respecting patients as an integral part of the nursing role but did not value all patients equally. More respect was experienced towards patients who were perceived as particularly respect-worthy while nurses struggled to have respect for some 'difficult' patients.

Specific circumstances sometimes led to powerful unintentional internal attributions and disrespectful attitudes. Attitudes of conditional respect were therefore evident, even when attitudes of unconditional respect were also described.

Table 2. Themes and subthemes.

Theme Subthemes

Private self: personal attitudes towards patients

Recognition/unconditional and appraisal/conditional respect as additive

Internal attributions and affective reactions

Outward self: showing respect Showing warmth and support versus surface respect: minimising dissonance

Proficiency in respect as a communication skill

Reputational self: being perceived as respectful

Tension between the outward self as intended and perceived

Impact of reputational self on respectful care

\section{Recognition/unconditional and appraisal/conditional respect as additive.}

Beliefs in human equality and attitudes of unconditional respect were evident in Kelly and Jules: 'I don't disrespect anybody. That's just 'cause they've had a different upbringing. Makes no odds, we're all equals far as I'm concerned' (Kelly). However, it was clear that patients' behaviour also influenced nurses' respect for them, including for nurses who voiced beliefs in shared humanity and human worth, such that unconditional and conditional respect were additive. Indeed, nurses expressed having a particularly high level of respect for patients showing patience, bravery or a fascinating life history, for example, older people: there's like I say a story behind every person and if you are lucky enough to get a story and I love listening to them, it's . . . that makes you even respect them more I believe, you know, from my perspective 'cause you know that they've . . . they've probably had a lot harder life than you. (Kelly) 
At the same time, the nurses struggled to have respect for 'difficult' patients who were rude, aggressive or demanding but valued empathy. An empathic orientation generally enabled them to understand that the patient's behaviour was due to their circumstances, such as their illness, feeling worried, scared or vulnerable in the hospital environment - an understanding that developed with nursing experience and maturity - facilitating respect. For instance, Gabriel and Campbell found the behaviour of some people with dementia offensive but could respect them because they felt they were not responsible for it. Jules was able to withstand disrespectful patients and then understand the reason for their behaviour, taking comfort in knowing s/he was 'doing right' by them.

\section{Internal attributions and affective reactions.}

Certain situations elicited internal attributions and negative affective reactions that resulted in disrespectful attitudes towards patients in that the nurse perceived the patient as non-respect-worthy and/or felt little respect for them. Internal attributions also occasionally triggered a perceived attack to one's worth as a person, influencing attitudes. An empathetic orientation was not always sufficient, and participants sometimes saw patients' 'challenging' behaviour as deliberate, attributing the behaviour to negative intent or a flaw in character. For instance, Val made negative assumptions about a patient's character, which s/he later realised, on developing the relationship, to be incorrect:

' . . . so I was probably making an assumption just thinking gosh, this woman's a bit of a cold fish'.Wider societal views of civility, the organisational culture and nurses' professional status elicited such internal attributions, and powerful negative affective reactions of anger and frustration, making it difficult to value the patient. For instance, Rudy felt angry when a young patient refused the only bed they had in a ward with other older and poorly men:

... I'm not staying next to all these, they're all sheds and they're all dying and he's smelly in the corner. ( . . ) when he did come back and ( . . . ) he got what he wanted. He got the bed next door to the younger person. ( . . .)

I was so cross that he could say that openly as he's looking round at these five other gentlemen and not know that ... and think it was OK to do that [ . . . . I I . . I never thought I'd feel that angry towards anybody who I didn't know but I did. While the nurse justified her anger at the patient's behaviour by reference to his ageist remarks, this was reinforced by categorising him as a 'demanding patient', possibly due to his age:

... So I think that sometimes you will get those characters that are used to having things immediately or used to demanding and it being there and when they're ill sometimes it's exacerbated $(. .$.$) there could be some really poorly person erm ...$ in the corner $(. .$.$) but you've got somebody here demanding your attention because you're over there ( . . . ). Most people$ can see what's happening and very often you find it's the young ones .... (Rudy)

A view that younger less seriously ill patients are demanding and disrespectful appeared to be encouraged by Rudy personally valuing self-effacing behaviour when others are in greater need as a sign of respect and a belief this has become lost in the younger generation. Rudy explained that she was from an 'era where respect was respect' and people would wait patiently when someone was in greater need. At the time, Rudy struggled to see that the patient's behaviour was due to fear of dying and vulnerability as later explained by the patient's girlfriend.

Perceptions of the patient's behaviour as lacking consideration for others, as misusing the healthcare system, or as undermining, underpinned disrespectful attitudes and were exacerbated by other patient stereotypes. Some participants felt frustrated or angry by patients with addictions or with no signs of physical illness, perceived as attention-seeking:

... there is nothing physically wrong with them, you know that they come in just for the attention and it's difficult, it's difficult to spread your time between someone who's really poorly and needs you and someone that's just there abusing the system.... (Sam)

Val felt frustrated by 'tricky' patients who come in and ask nurses 'lots of loaded questions' to then second guess them, never satisfied with the answers, yet never asking the doctor their questions. Val perceived these patients as having 'a real agenda': 'I think over the years you can spot these people quite easily and they ... they literally ... what they're trying to do is just to try and catch you out ( . . ) trip you up'. Val and Campbell felt that patients valued doctors more than nurses: ' . . . when I was trying to help him ( . . . ) that wasn't good enough and when the consultant came round he was as nice as pie to him (laughs) which is always annoying ( . . . )' (Campbell). Glenn also felt there was no respect for nurses. The view that patients sometimes lack respect for nurses as professionals could also explain why Gabriel struggled to respect a patient who was abrupt and 
asking her or him for tissues she could easily reach, without being able to articulate the source of his or her frustration:

... I wasn't rude, you know, I would say that I was cool. ( . . . ) there's a lot of frustration and ( . . . I'm not very good at being able to step back a little bit from that $(\ldots) .$. it's . . . it's not tangible enough to . . . for you to be able to deal with it. ( . . . I I did feel there was like a bit of a . . . a power er . . thing going on . . .

Nurses found it particularly difficult to respect verbally abusive patients whose extremely rude and aggressive behaviour made them feel vulnerable. The inability to see an obvious reason for the patient's verbally abusive behaviour (such as dementia or an infection), the patient being repeatedly rude or the perception that the aggressive behaviour was under the patient's control further culminated in resentment and a need to stand up for themselves as persons deserving of respect: ' . . . you can't think of a good reason why they're like that and you think well, why are they being rude to me ( . . . ) It's like, you know, hang on, I'm a person as well so it . . it . . . it works both ways ( . . )' (Charlie).

\section{Outward self: showing respect}

Nurses endeavoured to show respect to patients; however, this could be either a warmer or a more detached/ surface response depending on their attitudes of respect. A competing psychological need for authenticity/internal congruence and proficiency in communication skills played an important role in influencing the form of communication.

\section{Showing warmth and support versus surface respect: minimising dissonance.}

Showing respect followed naturally from deep concern or respect for patients and took the form of extra care in making sure the patient's needs were met:

... you couldn't help but respect him . . . you couldn't help . . . do your best in that situation and make sure that erm . . . that his needs and he knows that you are listening to him $(\ldots)$. (Gabriel)

When such an attitude of respect for patients was not present, nurses still showed respect:

I can't imagine anybody being rude to a patient. You might think it sometimes (laughs) and count to ten in your head but I would never ever be rude to someone at all, $[\ldots$. . perhaps it's just not in my nature but I've just been taught that $[\ldots]$ you don't do things like that. (Campbell)

Normative/role expectations and positive attitudes towards the behaviour of showing respect motivated respectful behaviour in the absence of a respectful attitude towards the patient. However, in such situations, showing respect often took the form of not showing disrespect by not being rude, yet 'cool' (Gabriel).

Similarly, Campbell explains: 'I didn't get into conversation . . . I've come to do your IV antibiotics is that ok?, and that was it, I decided that the least I said to him was probably the best . . . ' Sam felt distressed caring for someone having a late termination of pregnancy, a situation s/he was unprepared for and went against his or her beliefs and talked about supporting this patient without 'having to be false', possibly allowing her or him to minimise emotional dissonance between feelings and behaviour:

I spoke to her, just like she was a normal person and ( . . ) it wasn't about she was having a termination, it was about we're gonna get your pain under control and . . . ( . . ) explaining things to her and . . . holding her hand, little simple things, you know, sitting with her while she was scared. It . . . it's not . . . it doesn't take much, it really doesn't. You don't have to bend over backwards and be false to someone.

\section{Proficiency in respect as a communication skill.}

The nurses appeared to vary in their ability to keep a respectful front. There were indications that this was not easy, with the risk that negative feelings slip through:

'I do . . . feel like having a little weep inside but I would never let them know, hopefully' (Val). Val and Sam found it particularly hard when the patient was aggressive or when they were under work pressures but Campbell described effective self-presentation strategies:

... it's hard sometimes [to respect a patient] if you get people that are really rude to you but I think you've just got to rise above that ( . . ) so you probably just better stay calm (laughs) and go along with some of the things they want, you know, it is difficult but ... I think I do it quite well ...

Campbell was aware that instances of 'subtle' disrespect could occur where the nurse is 'not rude but a bit sharp to a patient' but saw these as isolated instances or else they would be noted. 


\section{The reputational self: being perceived as respectful}

Nurses described challenges in being perceived as respectful because of differences in how behaviour was perceived or interpreted. Such challenges, coupled with the need for a positive professional reputation/ identity, negatively impacted on respectful communication.

\section{Tension between the outward self as intended and perceived.}

Despite nurses' strong investment in their professional roles and in giving patients the best care they could give, half of the participants explained they or other nurses could be perceived as disrespectful when not intending to be or aware of being disrespectful, which presented a challenge to gaining respect. Two of these pointed out a tension between nurses' behaviour and patients' or relatives' experiences of it:

... people's perceptions are all different erm. . . and ( . . . ) you can say something to someone in a certain way and somebody is gonna . . . can turn it round and . . . and make it in to something else ( . . . ) So something's been done but they've sort of seen it in a different way and you know, people's interpretations can be different. (Charlie)

This tension was linked to insufficient awareness of the patient's perspective and/or different beliefs in what it means to show respect. Non-verbal behaviours also appeared to play an important role, although nurses endorsed different beliefs on the need for genuineness for communicating respect. Some nurses attributed the tension to insufficient awareness of the patient's perspective: 'if you're kind of a happy jokey person and said 'right come on let's all get out of bed' some people would be fine whereas other people can't take it . . ' (Campbell). Kelly explained that nurses are likely to endorse different beliefs about what it means to be respectful based on their upbringing/values, past experiences and the care environment, since this is not formally taught. For instance, Campbell explained that when she trained as a nurse, respecting patients did not involve respecting their autonomy since patientswere not involved in their care. Alex and Charlie stressed that a lack of appreciation of generation differences in expressions of respect could lead to coming across as disrespectful, for instance younger nurses being informal when first addressing the older people.

Campbell also explained that you had to be careful about your choice of words and the manner in which you talk: 'it's interesting listening to the nurses speaking to other patients (laughs) you might think oh I don't think that sounded very good ... '. Similarly, Alex who often dealt with patient concerns explained that patients pick up on nurses' disrespectful non-verbal communication such as facial expressions. Some nurses may not be aware of this or could struggle to control their non-verbal behaviours when endeavouring to show a non-genuine professional respectful front. Three participants, including Campbell andVal, believed you could be respectful without feeling respectful, and respect could take the formof a more genuine or more superficial response depending on the patient's behaviour and the emotions elicited in the nurse: ' . . . there are some patients that you really absolutely adore and there are other patients that you . . . put up with but you still respect thembut it's a different sort of erm. . . feeling' (Riley). In contrast, Jules believed congruence between what you say and the manner in which you say it was necessary to show respect.

Impact of reputational self on respectful communication.

The perception that behaviour could be interpreted as disrespectful despite one's intentions sometimes led nurses to use strategies to protect their professional reputation. For instance, Charlie explained the need to carefully document care, taking time away from patient care: ' . . . if you have a conversation with somebody make sure it's documented ( . . . ) nowadays it's just everything's gotta be in black and white because . . . sometimes it's somebody's word against somebody else's ( . . . )'. Three participants also explained that experiencing a positive professional identity and happiness in the job were important for respectful care: ' . . if you're happy within your job and within your role I think it's easy to be respectful to people. I think if you're unhappy I think you just don't be bothered . . .' (Sam).

\section{Discussion}

The study identified three interconnected superordinate themes relating to nurses' experiences of communicating respect to patients and associated intra- and inter-personal influences at the level of the private, outward and reputational self. Despite respect being an important element of patient-centred and ethical care, to our knowledge this is the first qualitative study to provide an in-depth understanding of healthcare professionals' experiences of communicating respect. The findings provide important theoretical insights into the process of respectful communication and influencing factors and shed light on challenges involved, helping inform interventions to promote respectful care. 
Communicating respect was complex and challenging. Relating the findings to key components of the broad communication framework of Feldman-Stewart et al.,26 which integrates several classical and healthcare communication frameworks influences on respectful communication emerging from each of the three themes can be broadly categorised into a set of needs/goals, beliefs and emotions, skills, external sociocultural factors and a distinction between conveyed and received messages (Figure 1). Framework components were often interrelated; for instance, respectful attitudes and beliefs about the nature of communication facilitated genuineness in communication and reception of the message as respectful.

In the healthcare literature, respect is often equated with unconditional valuing of patients as persons. 1 Indeed, it can be given on the basis of one's humanity. 18 However, while some nurses displayed attitudes of unconditional respect, endorsing beliefs in human worth, respect was mostly conditional. Moreover, nurses displaying unconditional respect also held stronger feelings of appreciation for patients perceived to have admirable qualities of overcoming hardship, bravery and patience, showing unconditional and conditional respect to be additive. Promoting unconditional respect could, therefore, still result in disparities in respect experiences, highlighting the need to pay more attention to patients' qualities that attract (dis)respect. Nurses struggled to have respect for patients who were rude, demanding, confrontational, or asked difficult questions. Interestingly, these characteristics have previously been associated with the 'difficult' or 'unpopular' patient,34 but it appeared to be more specifically the perceived lack of consideration for other patients in greater need and their taking nurses away from patients in 'real' need or a view that the patients undervalued the nurse, that led to disrespectful attitudes towards them, as opposed to other aspects. Not al

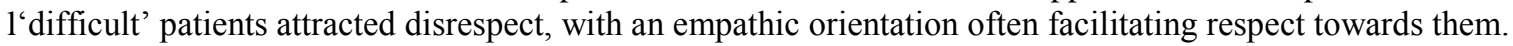
However, this was not always sufficient; wider societal views of civility, 35 nurses' lower professional status 36 and the organisational culture with a focus on medical rather than psychological aspects of care 37 led to powerful unintentional internal attribution processes resulting in the patient being perceived as deliberately undermining or lacking consideration for other patients or the healthcare system more broadly.

In line with attribution theory, 38 internal attributions were associated with negative affective reactions of anger and frustration that were difficult to control.

Figure 1. Framework of influences on communicating respect from nurses to their patients.

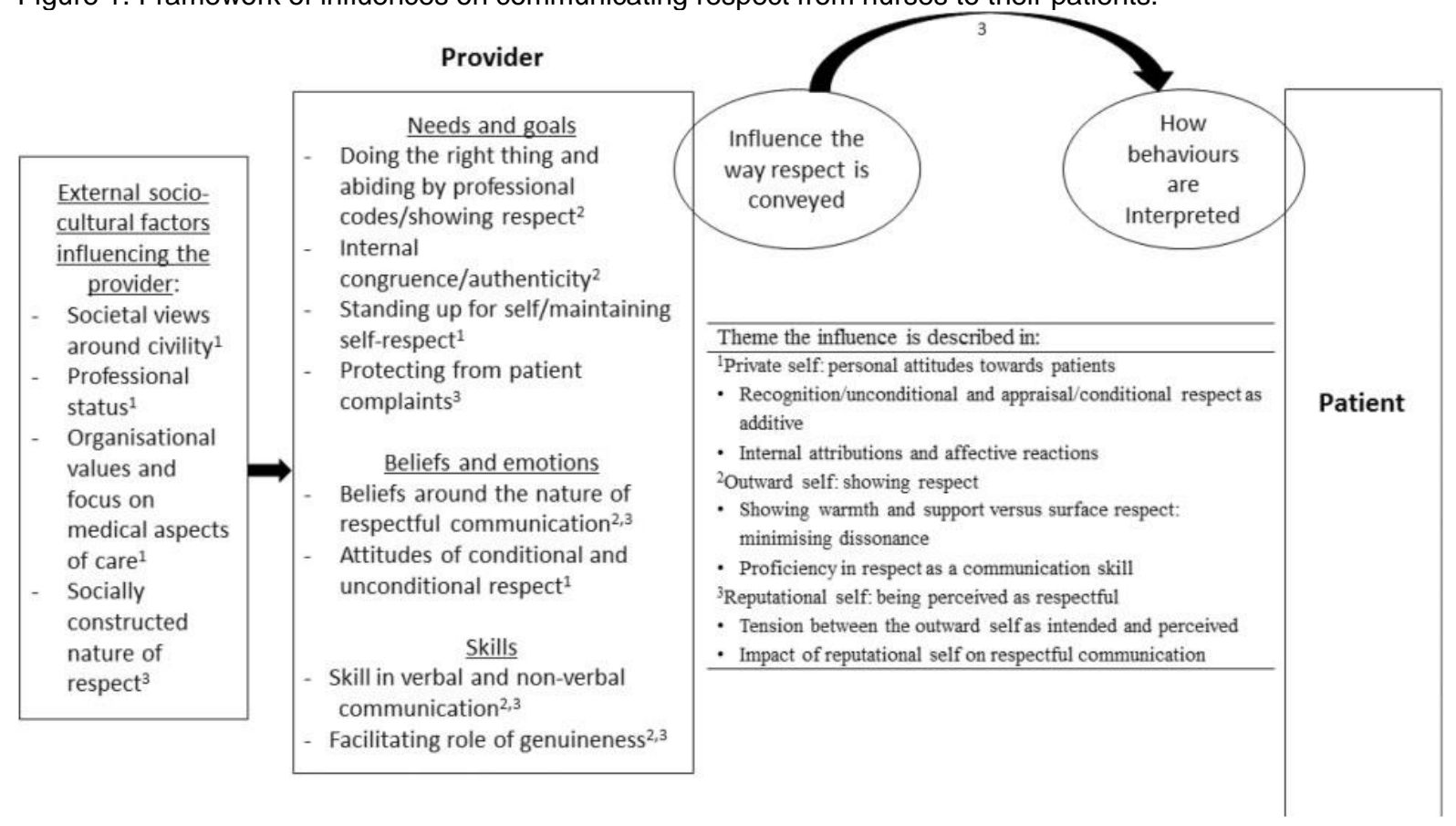

When nurses did not feel respect towards patients, they were not rude but adopted a more detached and distant inter-personal approach. Similarly, Beach et al.17 found American physicians to be less affectively positive towards patients whom they respected less, but our study shows this was evident even when positive intentions to communicate respect were held. Disrespectful attitudes resulting from feeling undervalued were accompanied by resentment, as well as a desire to affirm one's worth. Thus, despite positive intentions to communicate 
respect, this psychological need, as well as that of being internally congruent to maintain a sense of oneself as authentic rather than 'fake', presented barriers to communicating respect.

These findings emphasise the need to assist nurses with questioning the origins of their internal attributions and disrespectful attitudes, possibly in workshops and/or clinical supervision.

Nurses' beliefs regarding the nature of respectful communication were also problematic. Nurses did not necessarily perceive a polite but more detached approach to care as disrespectful, and some believed they could communicate respect in the absence of a respectful attitude towards the patient. Adopting such beliefs may be an important way to negotiate the conflict between personal attitudes and ideals of care, and might be encouraged by a paucity of literature discussing attitudes in conjunction with behaviours of respect and legitimised by the prescription of emotional detachment in some settings such as palliative care. 39 However, behaviours of care and warmth have been shown to make an important contribution to respectful communication from the patient's perspective and to explain sociodemographic disparities in experiences of respectful care. 6 Second, nurses' accounts suggested that genuine respect is likely to facilitate its communication.

Indeed, showing respect was described as a challenging communication skill, with a concern of negative feelings slipping through, and indications that patients might be picking up on non-intended nonrespectful nonverbal communication. Third, beliefs in needed congruence between verbal and non-verbal behaviour to communicate respect may facilitate respectful attitudes. A nurse who endorsed such beliefs adopted a different strategy; of 'withstanding' disrespectful behaviour in order to understand the reason behind the behaviour, allowing for the future development of a respectful attitude towards such patients.

The study underscores the need to more formally recognise respect as a complex attitudinal construct, with attitudinal influences on behaviour and success of communication, to reduce the risk that the concept of respect becomes open to different interpretations.

The study also underscores the need for more formal discussions on the socially constructed nature of respect 22 to be included in pre-registration and continuing development programmes in health and social care, as well as greater partnership with patients to understand their needs and expectations in relation to respect. Nurses' beliefs on what it means to show respect were based on their upbringing and social environment, with differences extending beyond culture, 40 which presented challenges to being perceived as respectful. In turn, the fear of patient complaints and the need to maintain a positive professional reputation led to adopting strategies that took time away from patient care, potentially threatening respectful communication, while the ability to maintain a role identity as a good and respectful nurse supported respectful communication intentions through happiness within and commitment to the nursing role. 41,42

These findings highlight the potentially circular nature of difficulties in communicating respect, which could increase threats to professional reputation and further hinder respectful communication.

A study limitation was that nurses were all from one hospital in the United Kingdom but several influencing factors, such as professional and ethical pressures to be respectful, some of the patient stereotypes and the perception of nursing as a lower status profession apply to healthcare delivery and systems in other countries as well, including the United States, Singapore and Sweden.2,37,43,44 Therefore, similar challenges in communicating respect might also be found elsewhere. Nurses provided rich data, enabling important insights, but the professional necessity to show respect and sensitivity of the research topic might have restricted full disclosure or reflection on certain experiences of care. The interviews were carried out not long after the Francis report was released in England, which negatively impacted on public perceptions of nurses, and could have influenced some of the findings relating to the reputational self in particular. However the high number of written complaints against nurses in 2017 and 201845 shows that similar challenges relating to critical patient attitudes are still very much alive today. Moreover, the discourse around respect and high-quality care has become more 'pronounced' in recent years with a renewed commitment to improve quality of care in the United Kingdom46 and other countries such as the United States.47 This further underscores the need to more deeply understand influences on respectful communication and the utility of the present findings.

To conclude, this study has deepened our understanding of intra- and inter-personal influences on the communication of respect. In addition, it identified several challenges to communicating respect that can be quite clearly understood within the framework developed, including the additive nature of unconditional and conditional respect, the influence of conditional attitudes of respect towards patients situated within a larger sociocultural context, competing psychological and professional needs/goals and differing understandings of respect. The overriding cultural and professional expectation for health practitioners to show equal respect to all patients, irrespective of situation, behaviour and sociocultural demands is hard to achieve in the reality of the clinical setting. The study advocates the need to more formally recognise the complex attitudinal and socially constructed nature of respect and urges education providers and organisations to more robustly prepare and support practitioners to develop respectful attitudes, in order to improve their communication of respect. To this end, it offers useful insight into the antecedents of respectful attitude. 


\section{References}

1. Department of Health. The NHS constitution. London: Department of Health (Crown Copyright), 2015.

2. International Council for Nurses. Code of ethics for nurses. Geneva: ICN, 2012.

3. Abdelrahman W and Abdelmageed A. Understanding patient complaints. BMJ Careers, http://careers.bmj.com/ careers/advice/Understanding_patient_complaints (2017, accessed 23 June 2018).

4. Chadwick A. A dignified approach to improving the patient experience: promoting privacy, dignity and respect through collaborative training. Nurse Educ Pract 2012; 12(4): 187-191.

5. Reader TW, Gillespie A and Roberts J. Patient complaints in healthcare systems: a systematic review and coding taxonomy. BMJ Qual Saf 2014; 23(8): 678-689.

6. Clucas C. Cancer patients' respect experiences in relation to perceived communication behaviours from hospital staff: analysis of the 2012-2013 National Cancer Patient Experience Survey. Support Care Cancer 2016; 24(4): 1719-1728.

7. Parse RR. Feeling respected - a parse method study. Nurs Sci Q 2006; 19: 52-56.

8. Clucas C and St Claire L. The effect of feeling respected and the patient role on patient outcomes. Appl Psychol Health Well Being 2010; 2(3): 298-322.

9. McCabe C. Nurse-patient communication: an exploration of patients' experiences. J Clin Nurs 2004; 13(1): 41-49. 10. Staniszewska SH and Henderson L. Patients' evaluations of the quality of care: influencing factors and the importance of engagement. J Adv Nurs 2005; 49(5): 530-537.

11. Thorne S, Oliffe JL, Stajduhar KI, et al. Poor communication in cancer care: patient perspectives on what it is and what to do about it. Cancer Nurs 2013; 36(6): 445-453.

12. Beach MC, Sugarman J, Johnson RL, et al. Do patients treated with dignity report higher satisfaction, adherence and receipt of preventive care? Ann Fam Med 2005; 3(4): 331-338.

13. Blanchard J and Lurie N. Respect: patients' reports of disrespect in the health care setting and its impact on care. J Family Pract 2004; 53: 721-730.

14. Street RL Jr, Makoul G, Arora NK, et al. How does communication heal? Pathways linking clinician-patient communication to health outcomes. Patient Educ Couns 2009; 74(3): 295-301.

15. Yu J and Kirk M. Measurement of empathy in nursing research: systematic review. J Adv Nurs 2008; 64(5): 440-454.

16. Care Quality Commission. Guidance for providers on meeting the regulations, https://www.cqc.org.uk/sites/ default/files/20150324_guidance_providers_meeting_regulations_01.pdf (2015, accessed 3 August 2018).

17. Beach MC, Roter DL, Wang N, et al. Are physicians' attitudes of respect accurately perceived by patients and associated with more positive communication behaviors. Patient Educ Couns 2006; 62(3): 347-354.

18. Lalljee M, Laham SM and Tam T. Unconditional respect for persons: a social psychological analysis. Gruppendyn Organisations 2007; 38(4): 451-464.

19. Frei JR and Shaver PR. Respect in close relationships: prototype definition, self-report assessment and initial correlates. Pers Relatsh 2002; 9(2): 121-139.

20. Hendrick S and Hendrick C. Measuring respect in close relationships. J Soc Pers Relat 2006; 23(6): 881-899.

21. Van Quaquebeke N and Eckloff T. Defining respectful leadership: what it is, how it can be measured, and another glimpse at what it is related to. J Bus Ethics 2010; 91(3): 343-358.

22. Grover SL. Unraveling respect in organization studies. Hum Relat 2014; 67(1): 27-51.

23. Rogers C. On becoming a person: a therapist's view of psychotherapy. London: Constable, 1967.

24. Riley JB. Communication in nursing. St Louis, MI: Elsevier Health Sciences, 2015.

25. Huizinga MM, Cooper LA, Bleich SN, et al. Physician respect for patients with obesity. J Gen Intern Med 2009;

24(11): 1236-1239.

26. Feldman-Stewart D, Brundage MD and Tishelman C. A conceptual framework for patient-professional communication: an application to the cancer context. Psychooncology 2005; 14(10): 801-809, discussion $810-811$.

27. Ajzen I. Attitudes, personality and behaviour. 2nd ed: Maidenhead: Open University Press, 2005.

28. Chapman H and Clucas C. Student nurses' views on respect towards service users - an interpretative phenomenological study. Nurse Educ Today 2013; 34(3): 474-479.

29. Hoeve Y, Jansen G and Roodbol P. The nursing profession: public image, self-concept and professional identity. J Adv Nurs 2014; 70(2): 295-309.

30. Dovidio JF and Fiske ST. Under the radar: how unexamined biases in decision-making processes in clinical interactions can contribute to health care disparities. Am J Public Health 2012; 102(5): 945-952.

31. Smith JA, Flowers P and Larkin M. Interpretative phenomenological analysis: theory, method and research. London: SAGE, 2009.

32. Elliott R, Fischer CT and Rennie DL. Evolving guidelines for the publication of qualitative research studies in 
psychology and related fields. Br J Clin Psychol 1999; 38(Pt 3): 215-229.

33. Francis R. The Mid Staffordshire NHS Foundation Trust Public Inquiry, http://www.midstaffspublicinquiry.com/ report (2013, accessed 10 October 2015).

34. RobinerWN and Petrik ML.Managing difficult patients: roles of psychologists in the age of interdisciplinary care. J Clin Psychol Med Settings 2017; 24(1): 27-36.

35. Eyres H. Civilisation, or just civility? The slow lane. Financial Times, 15 October, 2011, p. 18.

36. Royal College of Nursing (RCN). RCN employment survey. London: Labour Research Department, 2015.

37. Van Boekel LC, Brouwers EP, Van Weeghel J, et al. Stigma among health professionals towards patients with substance use disorders and its consequences for healthcare delivery: systematic review. Drug Alcohol Depend 2013; 131(1): 23-35.

38. Weiner B. Judgments of responsibility: a foundation for a theory of social conduct. New York: Guilford Press, 1995.

39. Funk LM, Peters $S$ and Roger KS. The emotional labor of personal grief in palliative care: balancing caring and professional identities. Qual Health Res 2017; 27(14): 2211-2221.

40. Mackenzie $\mathrm{L}$ and Wallace $\mathrm{M}$. The communication of respect as a significant dimension of cross-cultural communication competence. Cross-Cultural Comm 2011; 7(3): 10-18.

41. Burke PJ and Stets JE. Trust and commitment through self-verification. Soc Psychol Q 1999; 62: 347-366.

42. McCarthy J and Gastmans C. Moral distress: a review of the argument-based nursing ethics literature. Nurs Ethics 2015; 22(1): 131-152.

43. Eriksson U and Svedlund M. Struggling for confirmation - patients' experiences of dissatisfaction with hospital care. J Clin Nurs 2007; 16(3): 438-446.

44. Tay LH, Ang E and Hegney D. Nurses' perceptions of the barriers in effective communication with inpatient cancer adults in Singapore. J Clin Nurs 2012; 21(17-18): 2647-2658.

45. Health and Social Care Information Centre. Data on written complaints in the NHS, https://files.digital.nhs.uk/5B/ D86467/Data\%20on\%20Written\%20Complaints\%20in\%20the\%20NHS\%202017-18\%20Report.pdf (2018, accessed 14 January 2019).

46. NHS England. Nursing, midwifery and care staff: leading change, adding value. https://www.england.nhs.uk/ leadingchange/ (accessed 18 January 2019).

47. CMS.gov: Centers for Medicare and Medical Services. The hospital Value-Based Purchasing (VBP) program, https://www.cms.gov/Medicare/Quality-Initiatives-Patient-Assessment-Instruments/Value-Based-Programs/

HVBP/Hospital-Value-Based-Purchasing.html (accessed 26 January 2019). 